Universidade Tecnológica Federal do Paraná - UTFPR

Campus Ponta Grossa - Paraná - Brasil

ISSN: 1981-3686/ v. 9, n. 2: p. 1847-1859, 2015

D.O.I.:10.3895/rbta.v9n2.1676
Revista Brasileira de Tecnologia

Agroindustrial

\title{
DESENVOLVIMENTO E AVALIAÇÃO DA QUALIDADE DA POLPA E EXTRATO DE MIRTILO (Vaccinium myrtillus) EM PÓ
}

\section{DEVELOPMENT AND EVALUATION OF THE QUALITY OF POWDER PULP AND EXTRACT OF BLUEBERRY (Vaccinium myrtillus)}

\author{
Fernanda Izabel Garcia da Rocha Concenço ${ }^{1}$; Paulo César Stringheta ${ }^{2}$; Afonso Mota Ramos ${ }^{3}$; \\ Igor Hiroshi Tedyama de Oliveira ${ }^{4}$; Roberta de Souza Leone ${ }^{5}$ \\ 1,2,3,4 Universidade Federal de Viçosa - UFV - Viçosa - Brasil \\ fernanirocha@yahoo.com.br, stringap@ufv.br, amramos@ufv.br, igorhiroshi@hotmail.com \\ ${ }^{5}$ Universidade Federal do Paraná - UFPR - Curitiba - Brasil \\ robertasleone@gmail.com
}

\begin{abstract}
Resumo
Objetivou-se com este trabalho obter corante natural, na forma de pó, a partir do extrato e da polpa de mirtilo (Vaccinium myrtillus), bem como estudar as propriedades dos compostos bioativos dos produtos finais. As amostras da polpa e extrato de mirtilo em pó foram preparadas com maltodextrina $10 \mathrm{DE}(20 \%)$, e desidratadas por dois métodos de secagem (atomização e liofilização). Foram avaliados antocianinas totais por espectrofotometria e CLAE, polifenóis, atividade antioxidante por 2,2-difenil-1-picrilhidrazil (DPPH). Não houve efeito dos métodos de secagem utilizado para as variáveis polifenóis totais e percentagem de atividade sequestrante por DPPH para a polpa de mirtilo em pó. O teor de antocianinas e polifenóis foi superior no extrato em pó quando a secagem foi realizada em liofilizador, com 2938,94 mg/100g de antocianinas e $7680 \mathrm{mg}$ AGE/100g de polifenóis. A percentagem da atividade antioxidante por DPPH do extrato foi superior quando a secagem foi realizada em atomização, com 74,9\% de capacidade sequestrante.
\end{abstract}

Palavras-chave: Secagem, corante natural, antocianinas.

\section{Introdução}

A preferência do consumidor por alimentos naturais e saudáveis é crescente em todo o mundo. A literatura científica aponta cuidados com a ingestão dos corantes sintéticos, a respeito do grande uso deles pelas indústrias de alimentos e bebidas.

A toxicidade apresentada por vários corantes artificiais utilizados por longo período, fez destes pigmentos uma espécie de aditivo indesejável ao consumidor. $\mathrm{O}$ uso dos corantes naturais, pode aumentar o custo final dos alimentos processados, em contrapartida pode oferecer produtos mais saudáveis (CARVALHO, 1992).

As pesquisas, além de definir limites de tolerância para corantes artificiais permitidos, já contribuíram para a proibição do uso de vários compostos em muitos países (CONSTANT, 2003). Foram proibidos, por exemplo, amarelo sólido, até então muito empregado em gelatinas; laranja GGN, usado em pós para sorvetes; vermelho sólido, para recheios e revestimentos de biscoitos; azul de alizarina, corante em óleos emulsionados e gelatinas; e o escarlate $\mathrm{GN}$, com uso em recheios de 
confeitarias (CORANTES NATURAIS, 1997).

A substituição dos corantes artificiais por naturais ainda apresenta dificuldades em virtude de questões relacionadas à estabilidade. O sucesso para o emprego de corantes naturais reside em saber como controlar e processar a matéria-prima nas etapas de extração, purificação e formulação do corante, para obter alto rendimento e qualidade do produto final (FALCÃO et al., 2003).

Domingues et al. (2002) já relatava a crescente utilização de alimentos desidratados. A desidratação, tanto por atomização como por liofilização, gera produtos de maior valor nutritivo, estáveis e versáteis, podendo ser utilizados como aromatizantes, corantes, edulcorantes, vitaminas, minerais, acidulantes, temperos e medicamentos.

A secagem por atomização e por liofilização ocasionam pequenas perdas do pigmento antociânico, não sendo detectada presença do composto degradado no produto em pó (CONSTANT, 2003). Além disso, a armazenagem do produto na forma de pó é mais conveniente que na forma líquida, pois é de fácil manuseio, possui vida útil mais longa, ocasiona redução de custos no transporte e proporciona disponibilidade durante o ano inteiro.

O Mirtilo (Vaccinium myrtillus), é uma pequena fruta rica em compostos antociânicos, que vem sendo associado à ingestão de uma dieta saudável, devido também em parte às propriedades funcionais dos compostos que possui. Uma alternativa para a preservação do mirtilo é a sua desidratação pelo processo de atomização (spray drying) ou por liofilização, que permitem a obtenção de polpa e extrato de mirtilo desidratado com elevado teor de compostos bioativos. A desidratação, além de ser utilizada como método de conservação, objetiva também o refinamento do alimento resultando na oferta de um novo produto no mercado.

Nesse contexto objetivou-se, com este trabalho, obter o corante natural em pó, a partir do mirtilo variedade Bluegem, utilizando-se como fonte o extrato e a polpa deste fruto, e avaliar o efeito dos processos de secagem por atomização por atomização e liofilização, nas amostras obtidas.

\section{Material e Métodos}

O trabalho foi desenvolvido no Laboratório de Pigmentos Naturais e Secagem da Universidade Federal de Viçosa, localizada na cidade de Viçosa-MG, Brasil. Foi utilizada polpa e extrato de mirtilo, grupo Rabbiteye, variedade "Bluegem", produzida no Município de Antônio Carlos/MG, safra 2007/2008.

Foi utilizada maltodextrina na forma de pó branco como estabilizante, devido a fácil dissolução com dextrose equivalente 10 (DE) e sabor levemente doce. Embalagens de polietileno 
de alta densidade foram utilizadas para o acondicionamento das amostras obtidas.

Para a preparação da polpa, $2 \mathrm{Kg}$ de mirtilo foram pesados e colocados diretamente em água a $90{ }^{\circ} \mathrm{C}$ e mantidos por um minuto para inativação enzimática (branqueamento), sendo posteriormente encaminhada para a etapa de separação da polpa e casca por centrifugação. Para a preparação da polpa foi utilizado processador doméstico Walita, modelo R1-1861. Em seguida a polpa foi filtrada em tecido fino e posteriormente em papel Whatman $\mathrm{n}^{\circ} 1$ a vácuo, em funil de Buchner. $\mathrm{O}$ armazenamento foi feito em frascos âmbar. As polpas foram congeladas a temperatura de $-18{ }^{\circ} \mathrm{C}$ em freezer convencional para utilização durante os métodos de secagem.

Para a obtenção do extrato, $2,4 \mathrm{Kg}$ de mirtilo foram pesados, triturados em liquidificador e deixados em repouso em ausência de luz por $24 \mathrm{~h}$ sob refrigeração, em etanol $70 \%$ (v/v) acidificado com $\mathrm{HCl} 1,5 \mathrm{~N}$ até $\mathrm{pH} 2,0$.

Após $24 \mathrm{~h}$ as amostras foram filtradas em tecido fino e novamente em papel Whatman $\mathrm{n}^{\circ} 1$ a vácuo, em funil de Buchner. Para a evaporação do etanol a amostra foi concentrada em evaporador a vácuo a $\pm 40^{\circ} \mathrm{C}$. Para extração do material lipídico, três lavagens com $10 \mathrm{~mL}$ da mistura éter etílico: éter de petróleo (1:1) foram realizadas em funil de separação. $\mathrm{O}$ armazenamento foi feito em frascos âmbar, e os extratos congelados a temperatura de $-18{ }^{\circ} \mathrm{C}$ em freezer convencional.

Para a secagem da polpa e extrato de mirtilo foram utilizados $45 \mathrm{~mL}$ de polpa e do extrato para cada repetição de secagem no liofilizador, sendo adicionados $20 \%$ de maltodextrina (agente estabilizante) $10 \mathrm{DE}$ (dextrose equivalente). As condições de secagem por liofilização foram: pressão $4,2 \mathrm{~mm} \mathrm{Hg}$, temperatura de congelamento $-75{ }^{0} \mathrm{C}$, temperatura do condensador de $-40 \pm 5$ ${ }^{\circ} \mathrm{C}$ e temperatura de trabalho $-30 \pm 1{ }^{0} \mathrm{C}$. O tempo de processo foi de aproximadamente sete horas. $\mathrm{O}$ material se encontrava congelado em camadas finas de $5 \mathrm{~mm}$, em placas de vidro com diâmetro de $10 \mathrm{~cm}$.

Os produtos foram recolhidos na forma de pó e acondicionados em recipientes de polietileno para acondicionamento sob refrigeração, em temperatura de $8{ }^{\circ} \mathrm{C}$ para posteriores análises.

Para a secagem por atomização a polpa e o extrato de mirtilo foram utilizados como núcleo a ser encapsulado e a maltodextrina como agente encapsulante. Foram preparadas emulsões com as amostras com hidratação do agente encapsulante, adição do material a ser encapsulado e homogeneização da emulsão por cerca de 20 minutos em agitador magnético.

Foram utilizados $50 \mathrm{~mL}$ de polpa e extrato para cada repetição de secagem no atomizador, adicionados $20 \%$ de maltodextrina $10 \mathrm{DE}$ (dextrose equivalente) como estabilizante e $50 \mathrm{~mL}$ de água destilada a esta mistura.

As amostras foram submetidas à secagem em atomização Büchi 190. As condições de 
secagem por atomização foram: temperatura do ar de entrada de $170 \pm 10{ }^{\circ} \mathrm{C}$; temperatura do ar de exaustão $90 \pm 5{ }^{\circ} \mathrm{C}$. A quantidade de amostra atomizada para cada repetição foi em média de 100 $\mathrm{mL}$, e o tempo de secagem foi em torno de 15 a 20 minutos. Os produtos foram recolhidos na forma de pó e acondicionados em recipientes de polietileno armazenados sob refrigeração à temperatura de $8{ }^{\circ} \mathrm{C}$ para posteriores análises.

O teor de antocianinas totais, tanto na polpa como no extrato em pó, foi determinado por espectrofotometria de acordo com Lees e Francis (1972). Inicialmente 0,5 g do extrato foi diluída em $10 \mathrm{~mL}$ de etanol:HCl 1,5 N (85:15 v/v) e a solução levada à leitura espectrofotométrica de absorbância no comprimento de onda de $535 \mathrm{~nm}$. Para a determinação da concentração de antocianinas da polpa, $1 \mathrm{~g}$ da amostra foi diluída em 2,0 mL de etanol 70\% acidificado com $\mathrm{HCl}$. Após esta etapa, $1 \mathrm{~mL}$ da amostra foi diluída com $10 \mathrm{~mL}$ de etanol:HCl (85:15 v/v) e levada à leitura espectrofotométrica da absorbância em comprimento de onda de $535 \mathrm{~nm}$.

As análises qualitativas das antocianinas foram realizadas por CLAE, no laboratório de vitaminas, do Departamento de Nutrição e Saúde da Universidade Federal de Viçosa. O sistema de cromatografia líquida de alta eficiência foi composto de bomba de alta pressão, modelo LC-10AT VP; injetor automático com "loop" de $20 \mu 1$, modelo SIL-10AF e detector de arranjo de diodos UVvisível, modelo SPD-M10A. O sistema foi controlado pelo software Multi System, Class Vp 6.12. As condições para análise foram: coluna cromatográfica RP-18 MERCK (Li Chrospher 100, partículas de $5 \mu \mathrm{m}$ de diâmetro, $250 \times 4 \mathrm{~mm}$ ); detector espectrofotométrico de arranjos de diodos, operando com comprimento de onda $530 \mathrm{~nm}$, fase móvel composta de água-metanol (6:4 v/v) com 2 mol. $\mathrm{L}^{-1} \mathrm{HCl}$ até atingir $\mathrm{pH} 2,5$, com fluxo de $0,5 \mathrm{~mL} / \mathrm{min}$ e tempo de corrida de $30 \mathrm{~min}$.

Para as amostras do extrato em pó foi utilizado $0,1 \mathrm{~g}$ de amostra ressuspendida em $5 \mathrm{~mL}$ da fase movél acidificada com $\mathrm{HCl}$. Para as amostras da polpa em pó foram utilizadas $1 \mathrm{~g}$ do pó ressuspendido em $2 \mathrm{~mL}$ de etanol 70\% acidificado com $\mathrm{HCl}$, para a extração do pigmento. Uma alíquota de $1 \mathrm{~mL}$ da polpa foi diluída em $5 \mathrm{~mL}$ da fase movél acidificada e as amostras foram filtradas em membrana FH 1.300, Millipore, com diâmetro do poro de 0,45 $\mu$ e imediatamente injetada no sistema CLAE. Os espectros foram adquiridos no comprimento de onda de $530 \mathrm{~nm}$, de acordo com Vendramini e Trugo (2004), e Stringheta (1991). Todos os reagentes empregados na fase móvel foram filtrados em sistema Millipore de filtração a vácuo e a seguir degaseificado em sistema de ultrasom (Ultrassonic Cleaner T-14 Odontobrás).

As análises de polifenóis totais na polpa e extrato em pó foram realizadas segundo metodologia citada por Shahidi e Naczk (1995), que utilizou o reagente de Folin-Denis. Após as diluições dos pós, em tubo de ensaio foram adicionados os seguintes componentes, em ordem: 1,0 $\mathrm{mL}$ da amostra, 7,5 $\mathrm{mL}$ de água destilada e $0,5 \mathrm{~mL}$ do reativo de Folin-Denis, sendo o tubo agitado 
vigorosamente. Os tubos foram deixados em repouso por três minutos, quando $1,0 \mathrm{~mL}$ de solução de bicarbonato de sódio saturada foi adicionado. Os tubos permaneceram em repouso por mais uma hora ao abrigo da luz sob temperatura ambiente, e a leitura espectrofotométrica da solução final foi feita a $725 \mathrm{~nm}$ contra um "branco". O "branco" foi preparado nas mesmas condições que a amostra, contanto que o volume da amostra foi substituído por $1,0 \mathrm{~mL}$ do solvente na qual esta foi preparada (etanol 70\%). A quantidade de polifenóis totais foi calculada com base na curva analítica de ácido gálico, preparada com concentrações variando entre 0 e $100 \mathrm{mg} / \mathrm{L}$. O conteúdo fenólico total foi expresso em AGE (ácido gálico equivalente) e obtido pela equação da curva analítica.

Todas as leituras espectrofotométricas foram realizadas em espectrofotômetro UV-1601 PC Shimadzu.

O método da determinação do potencial antioxidante foi baseado no descoloramento de uma solução composta por radicais estáveis $\mathrm{DPPH}^{\bullet}$ de cor violeta quando há adição de substâncias que podem ceder um átomo de hidrogênio. O princípio do método é a transferência de elétrons de um composto antioxidante para um radical livre, o $\mathrm{DPPH}^{\bullet}$, que ao se reduzir perde sua coloração púrpura (DUARTE-ALMEIDA, 2006).

A determinação da atividade antioxidante foi realizada seguindo a metodologia de avaliação da capacidade sequestrante de radicais 2,2-difenil-1-picrilhidrazil ( $\mathrm{DPPH}^{\bullet}$ ), descrita por Espín et al. (2000) e Pukalskas et al. (2002) com modificações, sendo analisada a porcentagem de moléculas do radical DPPH sequestrado após determinado tempo. Foi utilizado 0,5 g do extrato em pó, ressuspendido em $10 \mathrm{~mL}$ de etanol 70\%. Previamente foi preparada uma solução etanólica 95\% de DPPH $(0,1 \mathrm{mM})$ e misturada em cubeta de vidro com amostra do extrato nas proporções de 1,0 (extrato) para 3,0 mL (DPPH), em temperatura ambiente. Para a polpa de mirtilo foi utilizado $1 \mathrm{~g}$ do pó ressuspendido em $2 \mathrm{ml}$ de etanol 70\% acidificado com $\mathrm{HCl}$ para a extração do pigmento. Uma alíquota de $1 \mathrm{~mL}$ da polpa foi diluída em $5 \mathrm{~mL}$ de etanol $70 \%$ e misturada em cubeta de vidro nas proporções de 1,0 (polpa) para 3,0 mL (DPPH). Foram então realizadas leituras de absorbância no comprimento de onda de $517 \mathrm{~nm}$ em espectrofotômetro UV-1601 PC Shimadzu, no tempo zero e após 4 minutos de reação no escuro à temperatura ambiente.

Uma solução "branco" foi preparada contendo as mesmas concentrações de todos os componentes, substituindo 3,0 mL do radical DPPH por 3,0 mL de etanol 95\%. A quantificação foi realizada de acordo com a Equação 1 , onde $\left(\mathrm{DPPH}^{\circ}\right)^{\mathrm{f}}$ é a absorbância medida no tempo 4 minutos e $\left(\mathrm{DPPH}^{\circ}\right)^{\mathrm{o}}$ a absorbância medida no tempo zero.

$$
\% \text { atividade sequestrante }=\left[1-\left(\mathrm{DPPH}^{\bullet}\right)^{\mathrm{f}} /\left(\mathrm{DPPH}^{\bullet}\right)^{\mathrm{o}}\right] \times 100
$$


O delineamento experimental foi disposto no inteiramente casualizado com 5 repetições, e análise feita em triplicata tendo como fonte de variação os métodos de secagem para amostra de polpa e extrato de mirtilo.

Para avaliação da qualidade da polpa e extrato de mirtilo em pó, os dados foram submetidos a análise de variância pelo teste $\mathrm{F}$ ao nível de $5 \%$ de probabilidade, e as médias foram comparadas pelo teste t. O programa utilizado foi o Statistical Analysis System (SAS ${ }^{\circledR}$ ) versão 9.1 licenciado para a UFV.

\section{Resultados e Discussão}

Na Tabela 1 encontra-se o efeito dos métodos de secagem nos teores de antocianinas totais, polifenóis totais, percentagem da atividade sequestrante por DPPH e desvio padrão da polpa de mirtilo em pó.

Tabela 1 - Valores (médios \pm desvio padrão) dos teores de antocianinas totais, polifenóis totais, percentagem da atividade sequestrante por DPPH para obtenção da polpa de mirtilo em pó submetido a dois métodos de secagem.

\begin{tabular}{lcc}
\hline \multirow{2}{*}{ Análises } & \multicolumn{2}{c}{ Métodos de Secagem } \\
\cline { 2 - 3 } & $967,63 \pm 93,05^{\mathrm{a}}$ & $714,79 \pm 184,9^{\mathrm{b}}$ \\
\hline Antocianinas totais $^{1}(\mathrm{mg} / 100 \mathrm{~g})$ & $3210 \pm 1,52^{\mathrm{a}}$ & $3300 \pm 0,19^{\mathrm{a}}$ \\
Polifenóis totais $^{1}(\mathrm{mg} \mathrm{AGE} / 100 \mathrm{~g})$ & $32,46 \pm 6,76^{\mathrm{a}}$ & $29,66 \pm 6,46^{\mathrm{a}}$ \\
\% Atividade sequestrante (DPPH) & & \\
\hline
\end{tabular}

Médias seguidas de letras diferentes na linha diferem entre si pelo teste t ao nível de $5 \%$ de probabilidade. ${ }^{1}$ Base seca \pm desvio padrão

Não houve efeito dos métodos de secagem $(\mathrm{p}>0,05)$ utilizado para as variáveis polifenóis totais, percentagem de atividade sequestrante por DPPH para a polpa de mirtilo em pó.

O teor de antocianinas na polpa foi influenciado pelo método de secagem, sendo que polpa liofilizada apresentou $967,63 \mathrm{mg} / 100 \mathrm{~g}$ de antocianinas, enquanto a secagem por atomização resultou em 714,79 $\mathrm{mg}$ de antocianinas por $100 \mathrm{~g}$ de polpa desidratada (Tabela 1 ).

A liofilização é uma técnica que resulta em produtos desidratados de alta qualidade devido à ausência de água líquida e das baixas temperaturas exigidas no processo. O estado sólido da água durante a secagem por liofilização também protege a estrutura primária e minimiza mudanças na forma do produto (RATTI, 2001), contribuindo para preservar componentes como os pigmentos naturais (GEORGE e DATTA, 2002). Como consequência, a secagem em liofilizador mostrou uma 
concentração de antocianinas no produto final desidratado ao redor de $35 \%$ superior ao obtido quando a secagem foi realizada por atomização.

Embora eficiente, a secagem por liofilização tem seu custo mais elevado e varia dependendo do tipo de matéria-prima, produto, embalagem, capacidade da planta e duração do ciclo. Em comparação com secagem de ar quente, dependendo do produto, os custos de liofilização são entre 4 e 8 vezes maiores (RATTI, 2001). Em virtude disso, sua utilização normalmente é mais adequada no processamento de produtos mais nobres ou de maior valor agregado. Embora tecnicamente superior, a viabilidade de sua aplicação no processamento de frutos de mirtilo para obtenção de corantes naturais deve ser avaliada quanto ao custo final do produto.

$\mathrm{Na}$ secagem em atomização, com a adição de maltodextrina, os produtos sofrem uma microencapsulação. Esta técnica é relativamente recente e tem a função de proteger o material encapsulado de fatores que possam vir a causar sua deterioração, tais como oxigênio, luz ou umidade. A técnica de microencapsulação mais utilizada na indústria de alimentos é a secagem por atomização, por ser considerado processo econômico e flexível, realizado em equipamento de fácil acesso, com menor custo que a liofilização, e que resulta em partículas de boa qualidade (GHARSALLAOUOUI, 2007).

A microencapsulação é utilizada para produtos que tenham em sua composição compostos sensíveis (DIB TAXI et al., 2003) aumentando a estabilidade do produto (TONON et al., 2009).

Embora neste experimento a liofilização tenha produzido uma polpa desidratada com concentração mais elevada de antocianinas (Tabela 1), resultados comparáveis entre métodos de secagem são constatados em várias situações. Resultados positivos estão normalmente associados a adição de algum agente que atue como estabilizador no processo, sendo que o agente mais adequado varia em função das características da matéria prima e também das particularidades do processo de secagem empregado. Duangmal et al. (2008), por exemplo, conseguiram retardar a degradação de antocianinas ao adicionar maltodextrina e trealose ao liofilizar extrato de Hibiscus sabdriffa L. Wagner e Wathesen (1995) encapsularam por secagem em atomização, carotenóides de suco de cenoura com amidos hidrolisados e constataram que amidos de maior DE (dextrose) proporcionaram maior retenção de $\alpha$ e $\beta$-caroteno. Barbosa et al. (2005) encapsularam bixina com goma arábica ou maltodextrina na secagem em atomização, concluindo que a goma arábica proporcionou maior retenção deste pigmento.

Não houve efeito dos métodos de secagem $(\mathrm{p}>0,05)$ utilizado para as variáveis polifenóis totais $^{1}$ e \% da atividade sequestrante por DPPH. Bora et al. (2005) determinaram a concentração de polifenóis do extrato em pó de folhas de Dicksonia sellowiana, popularmente conhecida como xaxim, e demonstraram que a concentração de polifenóis nas amostras aumenta proporcionalmente 
ao aumento da concentração da fonte do pigmento nessas amostras, e que o método de secagem por atomização utilizado não proporcionou perdas significativas nos teores de polifenóis.

Na Tabela 2 encontra-se o efeito dos métodos de secagem nos teores de antocianinas totais, polifenóis totais, percentagem da atividade sequestrante por DPPH e desvio padrão no extrato de mirtilo em pó.

O teor de antocianinas no extrato em pó foi superior quando a secagem foi realizada em liofilizador em relação a desidratação em atomização (Tabela 2).

Constant (2003) avaliou a estabilidade das antocianinas do extrato de açaí em pó, e concluiu que as desidratações por atomização ou por liofilização das amostras não contribuíram para a formação de complexos entre a antocianina e o carboidrato em uso, não sendo observada presença significativa de corante degradado no produto em pó. Os valores encontrados para as amostras de açaí em pó foram 29,4 e $32,9 \mathrm{mg} / 100 \mathrm{~mL}$, para o extrato com maltodextrina atomizado e liofilizado respectivamente, 22,4 e $23,4 \mathrm{mg} / 100 \mathrm{~mL}$ para o extrato com maltodextrina e betaciclodextrina atomizado e liofilizado respectivamente.

Tabela 2 - Valores (médios \pm desvio padrão) dos teores de antocianinas totais, polifenóis totais, percentagem da atividade sequestrante por DPPH para obtenção de extrato de mirtilo em pó submetido a dois métodos de secagem.

\begin{tabular}{lcc}
\hline \multicolumn{1}{c}{ Análises } & \multicolumn{2}{c}{ Métodos de Secagem } \\
\cline { 2 - 3 } & Liofilização & Atomização \\
\hline Antocianinas totais ${ }^{1}(\mathrm{mg} / 100 \mathrm{~g})$ & $2938,94 \pm 165,43^{\mathrm{a}}$ & $2162,51 \pm 160,76^{\mathrm{b}}$ \\
Polifenóis totais ${ }^{1}(\mathrm{mgAGE} / 100 \mathrm{~g})$ & $7680 \pm 1,19^{\mathrm{a}}$ & $6040 \pm 0,82^{\mathrm{b}}$ \\
& $57,95 \pm 8,47^{\mathrm{b}}$ & $74,90 \pm 2,54^{\mathrm{a}}$ \\
\hline Médias seguidas de letras diferentes na linha diferem entre si pelo teste t ao nível de $5 \%$ de probabilidade. \\
\hline Base seca \pm desvio padrão
\end{tabular}

Ersus e Yurdagel (2007) estudaram a microencapsulação por atomização de antocianinas extraídas de black carrot (Daucus carota L.), utilizando diferentes temperaturas de secagem (160 $200{ }^{\circ} \mathrm{C}$ ) e maltodextrinas com diferentes DEs $(10-30 \%)$, e observaram que para as maltodextrinas de maior DE, os ensaios realizados a $160{ }^{\circ} \mathrm{C}$ apresentaram maior retenção de antocianinas do que os demais. O conteúdo de antocianinas $(\mathrm{mg} / 100 \mathrm{~g})$ para as amostras microencapsuladas com maltodextrina $\left(10,20\right.$ e 30) DEs e temperatura de $160{ }^{\circ} \mathrm{C}$ foi de $499,39,630,92$ e $482,96 \mathrm{mg} / 100 \mathrm{~g}$.

Valduga et al. (2008) avaliaram antocianinas extraídas do bagaço de uva da cultivar Isabel (Vitis labrusca). A melhor condição para o encapsulamento e a secagem foi quando proporções iguais de maltodextrina e goma arábica foram utilizadas, obtendo $95 \mathrm{mg}$ de antocianinas $/ 100 \mathrm{~g}$, 
valor inferior quando comparado ao do presente estudo em extrato de frutos de mirtilo, com teor de $2162,51(\mathrm{mg} / 100 \mathrm{~g})$.

O teor de polifenóis também diferiu entre métodos de secagem, resultando em $7680 \mathrm{mg}$ de AGE por $100 \mathrm{~g}$ de extrato desidratado em liofilizador, e $6040 \mathrm{mg} / 100 \mathrm{~g}$ com secagem em atomização (Tabela 2). Chan et al. (2009) estudaram diferentes métodos de secagem de folhas de Alpinia zerumbet, Etlingera elatior, e Kaempferia galanga. Todos os métodos que envolveram calor (microondas, forno e secagem ao sol) resultaram em queda drástica no teor de polifenóis totais. $\mathrm{O}$ processo de secagem por liofilização não provocou queda significativa na concentração de polifenóis totais para as folhas de A. Zerumbet, apresentando concentração de $2550 \mathrm{mg}$ AGE/100g e E. Elatior com $3050 \mathrm{mg} \mathrm{AGE/100g.}$

A percentagem da atividade antioxidante por DPPH do extrato liofilizado foi de 57,95\% e de $74,9 \%$ com secagem em atomização (Tabela 2). Ersus e Yurdagel (2007) avaliaram a capacidade antioxidante dos extratos em pó de black carrot (Daucus carota L.) e verificaram que os extratos atomizados com maltodextrinas de 10 e 30 DEs não apresentaram diferença significativa na capacidade antioxidante apresentando 22,68 e 23,64 g/100 g respectivamente. Pesquisas anteriores (Camire et al., 2002, Moyer et al., 2002 e Wang et al., 1997) relataram que a atividade antioxidante tem alta correlação com a composição de antocianinas e polifenóis totais presentes em alimentos. As amostras do extrato de mirtilo em pó apresentaram uma concentração elevada de polifenóis e uma boa capacidade antioxidante.

A desidratação foi eficiente na preservação do mirtilo (variedade Bluegem), permitindo a obtenção de polpa e extrato com elevado teor de compostos bioativos. Além de ser utilizada como método de conservação, a desidratação objetiva também o refinamento do alimento, resultando na oferta de um novo produto no mercado e a disponibilidade em época de entresafra, onde não há a fruta no mercado. Além disso, a amostra em pó pode ser adicionada a produtos como iogurtes, sorvetes, gelatinas, bebidas isotônicas e sucos, com as finalidades tanto de atuar como corante natural, como de proporcionar propriedades funcionais a estes produtos.

Nas Figuras 01 e 02 são mostrados os perfis cromatográficos das antocianinas nas amostras da polpa atomizada e liofilizada de mirtilo em pó com $20 \%$ de maltodextrina. Nas figuras 03 e 04 são mostrados os perfis cormatográficos do extrato atomizado e liofilizado de mirtilo em pó com $20 \%$ de maltodextrina. Os espectros foram adquiridos no comprimento de onda de $530 \mathrm{~nm}$.

Verifica-se nos cromatogramas bom desempenho de separação dos pigmentos antociânicos por CLAE. 


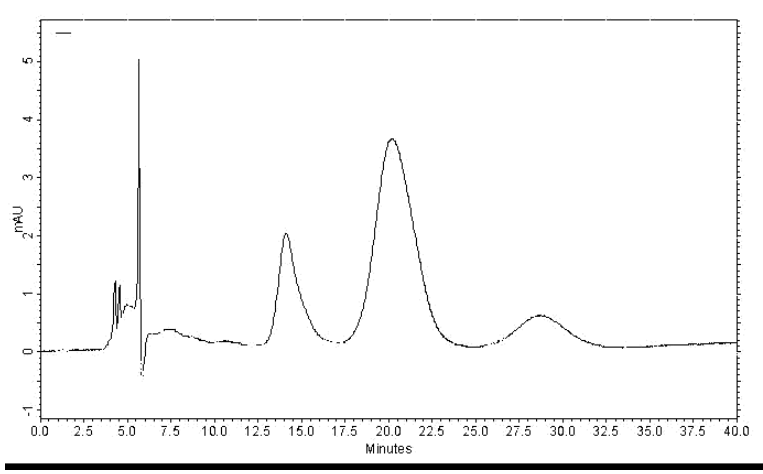

Figura 01 - Perfil cromatográfico da polpa atomizada de mirtilo em pó a $530 \mathrm{~nm}$, fase móvel composta de água-metanol $(6: 4 \mathrm{v} / \mathrm{v})$ com 2 mol.L ${ }^{-1}$ $\mathrm{HCl}(\mathrm{pH} 2,5)$, com fluxo de $0,5 \mathrm{~mL} / \mathrm{min}$ e tempo de corrida de $30 \mathrm{~min}$.

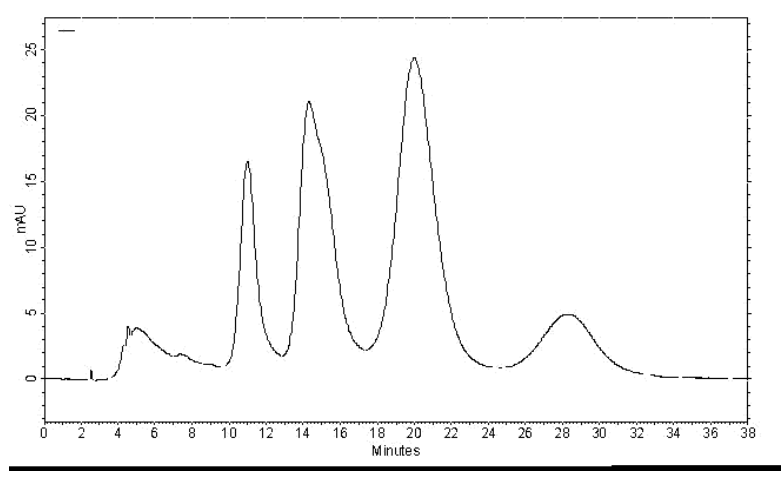

Figura 03 - Perfil cromatográfico do extrato atomizado de mirtilo em pó a $530 \mathrm{~nm}$, fase móvel composta de água-metanol $(6: 4 \mathrm{v} / \mathrm{v})$ com 2 mol.L $\mathrm{L}^{-1}$ $\mathrm{HCl}(\mathrm{pH} \mathrm{2,5})$, com fluxo de $0,5 \mathrm{~mL} / \mathrm{min}$ e tempo de corrida de $30 \mathrm{~min}$.

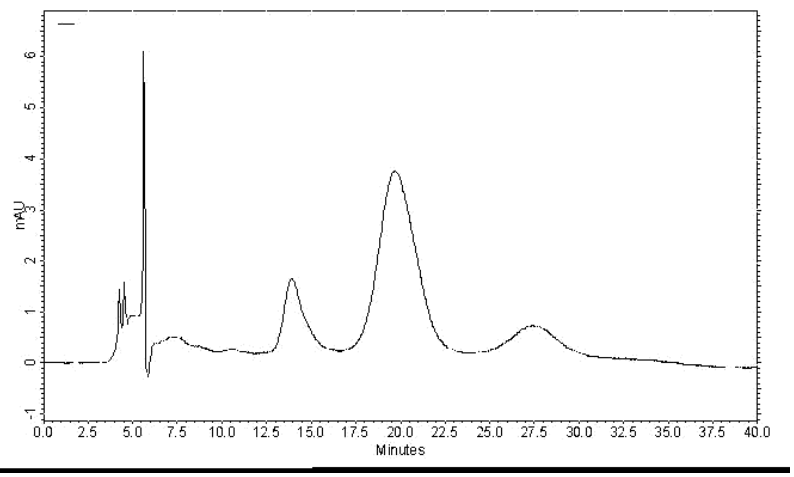

Figura 02 - Perfil cromatográfico da polpa liofilizada de mirtilo em pó a $530 \mathrm{~nm}$, fase móvel composta de água-metanol (6:4 v/v) com 2 mol.L ${ }^{-1} \mathrm{HCl}(\mathrm{pH} \mathrm{2,5),}$ com fluxo de $0,5 \mathrm{~mL} / \mathrm{min}$ e tempo de corrida de $30 \mathrm{~min}$.

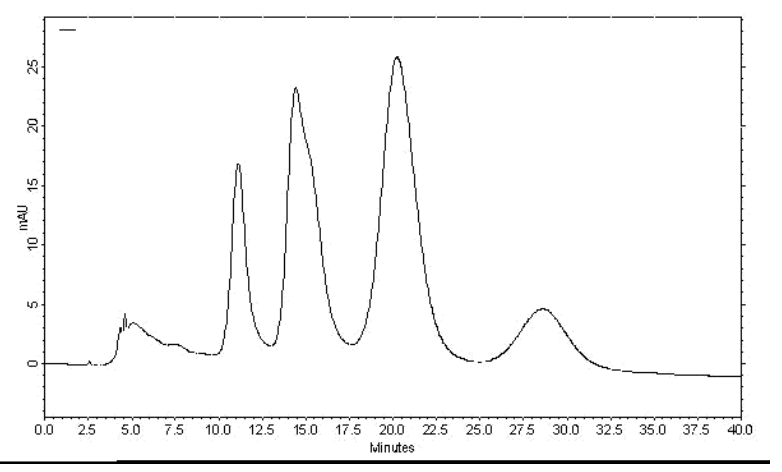

Figura 04 - Perfil cromatográfico do extrato liofilizado de mirtilo em pó a $530 \mathrm{~nm}$, fase móvel composta de água-metanol $(6: 4 \mathrm{v} / \mathrm{v})$ com 2 mol. $\mathrm{L}^{-1} \mathrm{HCl}(\mathrm{pH} 2,5)$, com fluxo de $0,5 \mathrm{~mL} / \mathrm{min}$ e tempo de corrida de $30 \mathrm{~min}$. 
Os autores concluíram através das informações obtidas que ambos os métodos de secagem utilizados foram eficientes para manter a qualidade das amostras em pó, quanto a retenção de antocianinas e polifenóis. O processo de atomização apresentou produtos em pó de melhor qualidade, com relação a aparência geral e solubilidade.

\begin{abstract}
The aim of this work was to obtain a natural dye, in powder form, from the extract and the pulp of blueberry (Vaccinium myrtillus), as well as to study the properties of the bioactive compounds on finished products. The formulations of pulp and extract of blueberry in powder were prepared with maltodextrin $10 \mathrm{DE}(20 \%)$, and dried by two drying methods (atomization and lyophilization). The following evaluations were made: total anthocyanins by spectrophotometry and HPLC, polyphenols, antioxidant activity by DPPH. There was no effect of drying methods for the total polyphenols and percentage of sequestrant activity for the powder pulp of blueberry. The content of anthocyanins and polyphenols was higher in the powder extract when drying was performed on lyophilizer, with $2938.94 \mathrm{mg} / 100 \mathrm{~g}$ of anthocyanins and $7680 \mathrm{mg}$ AGE/100g of polyphenols. The percentage of antioxidant activity by DPPH on the extract was higher when drying was performed by atomization, with $74.9 \%$ of sequestrant capacity.
\end{abstract}

Key-words: Drying, natural colorant, anthocianins.

\title{
Referências
}

BARBOSA, M. I. M. J.; BORSARELLI, C. D.; MERCADANTE, A. Z. Light stability of spray-dried bixin encapsulated with different edible polysaccharide preparations. Food Research International, Madison, v. 38, p. 989994, 2005. http://dx.doi.org/10.1016/j.foodres.2005.02.018

BORA, K.; MIGUEL, O. G.; ANDRADE, C. A.; OLIVEIRA, A. O. T. Determinação da concentração de polifenóis e do potencial antioxidante das diferentes frações do extrato de folhas de dicksonia sellowiana. Visão Acadêmica, v. 6 , n. 2, p. $6-14,2005$. http://dx.doi.org/10.5380/acd.v6i2.6095

CAMIRE, M. E.; CHAOVANALIKIT, A.; DOUGHERTY, M. P.; BRIGGS, J. Blueberry and grape antocyanins as breakfast cereal colorants. Journal of Food Science, v. 67, 2002.

CARVAlHO, P. R. N. Potencialidade dos Corantes Naturais. Revista Brasileira de Corantes Naturais, v. 1, n. 1, p. $244-245,1992$.

CONSTANT, P .B. L. Extração, caracterização e aplicação de antocianinas de açaí (Euterpre oleralea, M.). Tese (doutorado). Brasil: Universidade Federal de Viçosa, 2003, $183 f$.

CORANTES NATURAIS: várias tonalidades, várias aplicações. Equipe técnica Chr. Hansen. Revista Engenharia de Alimentos, Julho, 1997 - n. 14. Editora RPA. São Paulo, SP.

CHAN, E. W. C.; LIM, Y. Y.; WONG, S. K.; LIM, K. K.; TAN, S. P.; LIANTO, F. S.; YONG, M. Y. Effects of different drying methods on the antioxidant properties of leaves and tea of ginger species. Food Chemistry, v. 113, p.166 - 172, 2009. http://dx.doi.org/10.1016/j.foodchem.2008.07.090

DIB TAXI, C. M. A.; MENEZES, H. C.; SANTOS, A. B.; GROSSO C. R. F. Study of the microencapsulation of camucamu (Myrciaria dubia) juice. Journal of Microencapsulation, v. 20, n. 4, p. 443-448, 2003. http://dx.doi.org/10.1080/0265204021000060291

DUANGMAL, K.; SAICHEUA, B.; SUEEPRASAN, S. Colour evaluation of freeze-dried roselle extract as a natural food colorant in a model system of a drink. Food Science and Technology, n. 41, p. 1437-1445, 2008. http://dx.doi.org/10.1016/j.lwt.2007.08.014

DOMINGUES, A. et al. Caracterização das propriedades físicas do suco de abacaxi (Ananás comosus) em pó desidratado por atomização otimizado através de análise de suporte de superfície de resposta. In: Congresso Brasileiro de Ciência e Tecnologia de Alimentos, 18., 2002, Porto Alegre, p. 1717 - 1720. 
DUARTE-ALMEIDA, J. M; SANTOS, R. J; GENOVESE, M. I; LAJOLO, F. M. Avaliação da atividade antioxidante utilizando sistema b-caroteno/ácido linoléico e método de seqüestro de radicais DPPH• Ciência e Tecnologia de Alimentos, v. 26, n. 2, 2006. http://dx.doi.org/10.1590/S0101-20612006000200031

ERSUS, S.; YURDAGEL, U. Microencapsulation of anthocyanin pigments of black carrot (Daucus carota L.) by spray drier. Journal of Food Engineering, v. 80, p. 805-812, 2007. http://dx.doi.org/10.1016/j.jfoodeng.2006.07.009

ESPÍN, J. C.; SOLER-RIVAS, C.; WICHERS, H. J.; GARCÍA-VIGUERA, C. Anthocyanin-based natural colorants: a new source of antiradical activity for foodstuff. Journal of Agricultural and Food Chemistry, v. 48, p. 1588-1592, 2000. http://dx.doi.org/10.1021/jf9911390

FALCÃO, L. D., BARROS, D. M., GAUCHE, C., BORDIGNON LUIZ, M. T. Copigmentação intra e intermolecular de antocianinas: uma revisão. Boletim do CEPPA, v. 21, n. 2, p. 351-366, 2003. http://dx.doi.org/10.5380/cep.v21i2.1170

GEORGE, J. P.; DATTA, A. K., Development and validation of heat and mass transfer models for freeze-drying of vegetable slices, Journal of Food Engineering, n. 52, p. 89 - 93, 2002. http://dx.doi.org/10.1016/S02608774(01)00091-7

GHARSALlAOUI, A.; ROUDAUT, G.; CHAMBIN, O.; VOILLEY, A.; SAUREL, R. Applications of spray drying in microencapsulation of food ingredients: An overview. Food Research International, v. 40, n. 9, p. 1107-1121, 2007. http://dx.doi.org/10.1016/j.foodres.2007.07.004

LESS, D. H.; FRANCIS, F. J. Standardization of pigment analysis. 1972.

MOYER, R. A .; HUMMER, K. E.; FINN, C. E.; FREI, B.; WROLSTAD, R. E. Anthocyanins, phenolics and antioxidant capacity in diverse small fruits. Journal of Agricultural and Food Chemistry, v. 50, p. 519 - 525, 2002. http://dx.doi.org/10.1021/jf011062r

PUKALSKAS, A.; BEEK, T. A. V.; VENSKUTONIS, R. P.; LINSSEN, J. P. H.; VELDHUIZEN, A. V.; De GROOT, A. Identification of radical scavengers in sweet grass (Hierochioe odorata). Journal of Agricultural and Food Chemistry, n. 50, p. 2914 - 2919, 2002. http://dx.doi.org/10.1021/jf011016r

RATTI, C. Hot air and freeze-drying of high - value foods: a review. Journal of Food Engineering, v. 49, p. 311-319, 2001. http://dx.doi.org/10.1016/S0260-8774(00)00228-4

SHAHIDI, F; NACZK, M. Food phenolics: sources, chemistry, effects and applications. 1. ed. Lancaster: Technomic Publishing Co, Inc., 1995. 331p.

STRINGHETA, P. C. Identificação da estrutura e estudo da estabilidade das antocianinas extraídas da inflorescência de capim gordura (Mellinis minutiflora, Pal de Beauv). Tese de Doutorado. Programa de pósgraduação em Ciência de Alimentos, UNICAMP, 1991.

TONON, R. V.; BRABET, C.; HUBINGER, M. D. Influência da temperatura do ar de secagem e da concentração de agente carreador sobre as propriedades físico-químicas do suco de açaí em pó. Ciência e Tecnologia de Alimentos, v.29, p. 444 - 450, 2009. http://dx.doi.org/10.1590/S0101-20612009000200034

VALDUGA, E.; LIMA, L .; PRADO, R .; PADILHA, F. F.; TREICHEL, H. Extração, secagem por atomização e microencapsulamento de antocianinas do bagaço da uva isabel (vitis labrusca). Ciência Agrotécnica, Lavras, v. 32, n. 5, p. $1568-1574,2008$.

VENDRAMINI, A.L.A.; TRUGO, L.C. Phenolic Compounds in Acerola Fruit (Malpighia punicifolia, L.). Journal of Brazilian Chemical Society, v. 15, n. 5, p. 664 - 668, 2004. http://dx.doi.org/10.1590/S0103-50532004000500009

WAGNER, L. A.; WATHESEN, J. J. Stability of spray-dried encapsulated carrot carotene. Journal of Food Science, London, v. 60, n. 5, p. 1048-1053, 1995. http://dx.doi.org/10.1111/j.1365-2621.1995.tb06290.x

WANG, H.; CAO, G.; PRIOR, R. L. Total antioxidant capacity of fruits. Journal of Agricultural and Food Chemistry, v. 44, p. 701-705, 1997. 
USDA US Department of Agriculture National Nutrient Database Standard Reference, Release 20 (2007). Nutrient content charts for frozen and canned blueberries are also available at this website. http://www.nal.usda.gov/fnic/foodcomp/search/index.htm. Acesso em: 15/08/2009.

VILA, M. T. R.; OLIVEIRA LIMA, L. C. O.; VILAS BOAS, E. V. B.; DOLL HOJO, E. T.; RODRIGUES, L. J.; FERREIRA DE PAULA, N. R. Caracterização química e bioquímica de goiabas armazenadas sob refrigeração e atmosfera modificada. Ciência e Agrotecnologia, v. 31, n. 5, 2007.

VILlATA, M. United States Highbush Blueberry Council Announces Best New Blueberry Product Contest Winners. Folson: North American Blueberry Council, 2007, 2p.

WANG, S.Y.; ZHENG, W. Oxygen radical absorbing capacity of phenolics in blueberries, cranberries, chokeberries, and lingonberries. Journal of Agricultural and Food Chemistry, v. 51, n. 2, p.873-878, 2003. http://dx.doi.org/10.1021/jf950579y

WILlS, R. B. H.; MULHOLLAND, E. E.; BROWN, B. I. Storage of two new cultivars of guava fruit of processing. Tropical Agriculture, Trinidad, v. 60, n. 3, p. 175-178, 1983.

Submetido em 07 out. 2013, Aceito para publicação em 23 jun. 2014, Publicado em 10 dez. 2015. 